\title{
BMJ Open Current therapy for the upper limb after stroke: a cross-sectional survey of UK therapists
}

\author{
Rachel Stockley (D) , ${ }^{1}$ Rosemary Peel, ${ }^{2}$ Kathryn Jarvis, ${ }^{2}$ Louise Connell ${ }^{2}$
}

To cite: Stockley $R$, Peel $R$, Jarvis $\mathrm{K}$, et al. Current therapy for the upper limb after stroke: a cross-sectional survey of UK therapists. BMJ Open 2019;9:e030262. doi:10.1136/ bmjopen-2019-030262

- Prepublication history and additional material for this paper are available online. To view these files, please visit the journal online (http://dx.doi org/10.1136/bmjopen-2019030262).

Part of these results were presented at the UK Stroke Forum in 2018.

Received 06 March 2019 Revised 30 July 2019 Accepted 03 September 2019

Check for updates

(C) Author(s) (or their employer(s)) 2019. Re-use permitted under CC BY-NC. No commercial re-use. See rights and permissions. Published by BMJ.

${ }^{1}$ School of Nursing, University of Central Lancashire, Preston, UK

${ }^{2}$ School of Health Sciences, University of Central Lancashire, Preston, UK

Correspondence to Dr Rachel Stockley; rstockley1@uclan.ac.uk

\section{ABSTRACT}

Objectives To survey the reported content, frequency and duration of upper limb treatment provided by occupational and physiotherapists for people after stroke in the UK.

Design A cross-sectional online survey was used. Description and analysis of the data were based on items from the Template for Intervention Description and Replication (Who, Where, What and How much).

Setting The online survey was distributed via professional and social networks to UK-based therapists.

Participants Respondents were occupational or physiotherapists currently working clinically in the UK with people after stroke. Over the 6 week data collection period, 156 respondents opened the survey, and 154 completed it. Respondents comprised 85 physiotherapists and 69 occupational therapists.

Results Respondents reported treating the upper limb a median of three times a week (range: 1 to 7) for a mean of 29 min (SD: 18). Most $(n=110)$ stated this was supplemented by rehabilitation assistants, family and/ or carers providing additional therapy a median of three times a week (range 1 to 7). Functional training was the most commonly reported treatment for people with mild and moderate upper limb deficits ( $>40 \%)$. There was much less consistency in treatments reported for people with severe upper limb deficits with less than $20 \%(n=28)$ reporting the same treatments.

Conclusions This study provides a contemporaneous description of reported therapy in the UK for people with upper limb deficits after stroke and a detailed template to inform standard therapy interventions in future research. Several evidence-based therapies were reported to be used by respondents (eg, constraint induced movement therapy), but others were not (eg, mental imagery). The findings also highlight that the current reported provision of upper limb therapy is markedly less than what is likely to be effective. This underlines an urgent need to configure and fund services to empower therapists to deliver greater amounts of evidence-based treatment for people with upper limb deficits after stroke.

\section{BACKGROUND}

Over 100000 people have a stroke each year in the UK. ${ }^{1}$ Improvements in acute medical care mean that more people survive than ever before, but many need significant rehabilitation to restore function. While two-thirds of people go on to walk independently after

\section{Strengths and limitations of this study}

The survey findings provide key detail about the frequency, intensity and content of therapy for differing severities of arm deficits after stroke.

- Unlike other surveys of therapy, the results also describe supplemental activities delivered by rehabilitation assistants and family/carers.

- Its findings can be used to design a standard therapy control intervention for future trials of upper limb interventions.

- The findings of the survey are limited by its reliance on self-report and an unknown response rate.

stroke, less than half have regained basic functions of the upper limb by 12 months, which markedly restricts their independence in activities of daily living and reduces their quality of life. ${ }^{2}$ This makes upper limb rehabilitation a significant and ongoing priority for people after stroke, clinicians and researchers.

An understanding of what current clinical therapy comprises is vital. It allows comparisons of guidelines and the research evidencebase to determine how well research evidence is being translated into routine practice and informs therapy provision. Furthermore, many trials in stroke rehabilitation compare experimental treatments to a standard or usual therapy, in order to evaluate the potential equivalence or superiority of new interventions. The increasing use of reporting guidelines to describe trials and interventions, such as the Template for Intervention Description and Replication (TIDieR) ${ }^{4}$ checklist has encouraged more detailed description of many experimental treatments in research trials. However, the same rigour in reporting is rarely applied when describing standard therapy in studies evaluating rehabilitative interventions in stroke. ${ }^{5}$ In published reports of stroke rehabilitation trials, almost half the number of words and references are used to describe and support 
control treatments compared with the experimental intervention. ${ }^{5}$ Underreporting of the components of standard treatment presents problems in the design, interpretation and implementation of the findings of these trials. First, it reduces confidence that participants in a standard therapy control arm received a clinically representative intervention, and so negatively impacts on the veracity of the trial's results. Second, readers of published trials may struggle to interpret differences between groups where one treatment (the standard therapy group) is ill-defined and/or unrealistic and make erroneous conclusions about the superiority of one treatment over another. Third, inadequate description means as it cannot be determined if standard therapies delivered across trials are similar, results from multiple studies cannot be compared and the opportunities for synthesis and meta-analysis are reduced.

In the last 10 years, the number of studies of interventions focussed on rehabilitation of the upper limb after stroke has grown rapidly. This is exemplified by large increases in the numbers of published papers found in updated Cochrane reviews and database searches (for example, a review of virtual reality for the upper limb rose from 12 included studies in 2015 to 22 in 2017, and a PubMed search using stroke AND upper limb yielded 354 studies in 2006 to 2007, increasing to 943 in 2016 to 2017) ${ }^{67}$ Despite this increase in research activity, recovery and rehabilitation of the upper limb after stroke remains a significant challenge, and so it is likely to continue to be a focus of research endeavour for many years to come. Accordingly, accurate reporting of standard therapy/ treatments is vital to inform future trial design and to ensure that their results are easily interpretable and reproducible.

In the UK, audits such as the Sentinel Stroke National Audit Programme (SSNAP) provide an indication of temporal elements of therapy (eg, average treatment time) but do not provide any indication of what treatment comprises. ${ }^{8}$ Several studies have sought to describe aspects of therapy provided in rehabilitation of the upper limb after stroke. Some have reported the content of therapy for the upper limb used in clinical trials, ${ }^{9}{ }^{10}$ but treatments delivered as part of a clinical trial may not necessarily reflect therapy routinely delivered in clinical practice. Similarly, others have developed upper limb treatment templates to standardise therapy in research trials ${ }^{11-13}$ however these templates seek to guide therapy or categorise current treatment, and so do not describe routine clinical practice. Several researchers have observed the number of repetitions, time given to and overall dose of therapy occurring during clinical therapy sessions for the upper limb ${ }^{1014-16}$ and others have observed and recorded the time spent on activities while staying in rehabilitation facilities. ${ }^{17-21}$ While these observational studies yield perhaps the most objective information about the intensity and provision of therapy, they are based on reports from a small number of international sites which limits their applicability to wider practice in the UK. Crucially, they do not typically provide details of the specific content of therapy.

In the UK, two studies have used surveys to gather information about therapy for the upper limb after stroke. One national survey in the UK found that exercises are prescribed by nearly all therapists for the upper limb of people after stroke, but did not investigate the content or duration of treatment undertaken with therapists. ${ }^{22}$ Others have surveyed UK stroke teams and used the opinions of expert panels to describe the duration, frequency and content of upper limb rehabilitation provided by UK stroke teams ${ }^{23}$. However, they did not consider the detailed content of activities nor those performed outside therapy sessions. It is also worth noting that both these studies were conducted several years ago, prior to publication of the latest Stroke Guidelines in $2016^{24}$ which may have altered practice.

Without a contemporaneous and detailed definition, standard therapy in rehabilitation trials for the upper limb after stroke risk being biased, unrealistic and unreflective of current clinical therapy, affecting the validity and usefulness of the trial results. Furthermore, a description of current clinical practice is needed to evaluate the implementation of research findings into therapeutic practice and to understand 'the state of the art' in upper limb stroke rehabilitation in the UK. Therefore, this study aims to describe the providers of therapy (who), the reported location (where), content (what), frequency and duration (how much) of upper limb therapy for people with different severities of arm involvement after stroke in the UK.

\section{METHODS}

A cross-sectional online survey - the Survey of Upper Limb Therapy after Stroke (SUPPLES UK, online supplementary file 2) was developed by two occupational and two physiotherapists and comprised 44 closed, Likert and free text items, using the Online Surveys tool (www. onlinesurveys.ac.uk; formerly known as Bristol Online Surveys). Questions were developed using the current UK stroke guidelines and previous investigations of the provision of upper limb therapy after stroke. ${ }^{22-24}$ The survey and item structure were guided by identified good practice in survey construction and the TIDieR checklist to facilitate replicable reporting of location (where), content (what), frequency and duration (how much) of the reported therapy. ${ }^{425}$ Sections included:

- Respondent demographics (where),

- Staff involved in delivery of therapy (who),

- Content (what),

- Frequency and dose of therapy (how much)

- Other activities/therapy provided outside of therapist-led treatments.

Respondents were asked to indicate treatments that they typically used for different severities of upper limb impairments after stroke, defined from the National Institutes of Health (NIH) Stroke Scale upper limb item (0 
and $1=$ mild - able to lift and hold arm up against gravity for $10 \mathrm{~s}$; $2=$ moderate - some effort against gravity, but the arm cannot get to or maintain the proper position and drifts down to the bed before $10 \mathrm{~s} ; 3$ and $4=$ severe - unable to move against gravity or no voluntary movement) ${ }^{26}$

The survey was piloted by three therapists, peer-reviewed and refined according to feedback. The final survey was distributed via professional channels, (Association of Chartered Physiotherapists Interested in Neurology (ACPIN), Royal College of Occupational Therapists Specialist Section - neurological section (RCOTSS-NS), Physiotherapy Frontline) and social networks (Twitter). It remained open for 6 weeks ( $1^{\text {st }}$ July 2018 to $13^{\text {th }}$ August 2018).

Respondents were provided with an information sheet (online) and consent was implied by completing the survey. They completed the survey anonymously, having first confirmed they were occupational or physiotherapists and that they were currently clinically working with stroke survivors.

\section{Patient and public involvement}

Patients and the public were not involved in this research.

\section{Analysis}

Demographic details, treatment frequencies and durations were summarised using descriptive statistics. Interval level data were reported using means and SD if they were normally distributed (after testing using Kolmogorov-Smirnov tests), while ordinal and nominal data used median and ranges. As some respondents worked across settings, their primary location of work was assumed to be where they spent at least $75 \%$ of their time. Where a range was provided by respondents in free text answers (eg, 20 to $30 \mathrm{~min}$ ), the mean was used and weekly frequencies were expressed as a fraction of 7 days a week (eg, every day $=7$ ). If respondents reported providing treatments more than once a day, this was expressed as a multiple (eg, twice daily treatment every day=14). Free text answers were initially listed and then coded into themes by one person (RP), and independently verified by another (RS). Any disagreements in coding were resolved by a third person (LC or KJ). The TIDieR framework was used to structure the analysis and presentation of results. This paper reports who provided treatments (Who; physiotherapists, occupational therapists, others), where respondents were based (Where), treatment content (What) and frequency and duration (When and How much). Analyses were undertaken using MS Excel and SPSS V.23.

\section{RESULTS}

\section{Respondent demographics}

One hundred and fifty-six people completed the two mandatory questions (confirming that they were an occupational or physiotherapist and that they were currently clinically working with stroke survivors at any stage of their recovery in the UK). Two respondents'

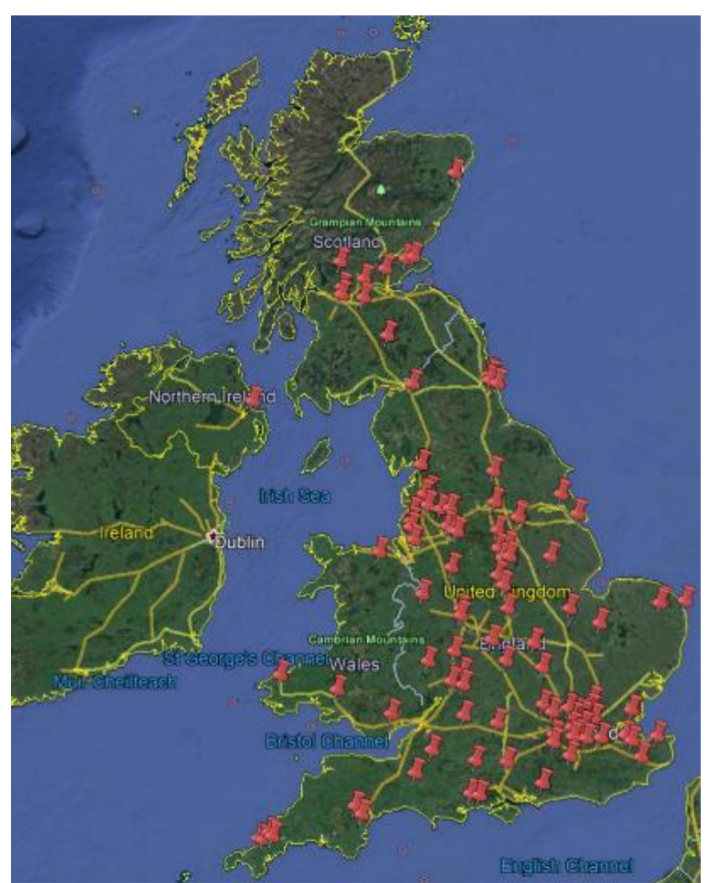

Figure 1 Geographical location of survey respondents $(n=154)$. Each pin represents a single postcode (first three or four digits).

data were excluded from further analysis as they had more than $50 \%$ of data missing (both physiotherapists). Respondents came from all over the UK and Northern Ireland (see figure 1). A TIDieR checklist was completed using the results (presented in a online supplementary file 3).

\section{Who?}

Respondents comprised more physiotherapists (PT) than occupational therapists (OT) (85 physiotherapists, 55\%; 69 occupational therapists $45 \%$ ). The majority of respondents reported an undergraduate degree as their highest qualification $(\mathrm{n}=79 ; 51 \%), 40$ had a master's degree (26\%) and 9 had a $\mathrm{PhD}(6 \%)$. Nine had completed some master's modules and/or had some postgraduate (PG) qualifications (PG certificate or similar; 6\%) while others stated that a diploma was their highest academic qualification $(\mathrm{n}=15,10 \%)$.

Respondents were a median of 16 years since qualification (range 1 to $36 ; n=154$ ). On average, respondents had worked with people after stroke for a median of 10 years (range 1 to $27 ; n=154$ ). They reported spending $70 \%$ of their clinical time working with people after stroke (SD 30; range 8 to $100 ; n=153$ ) and of their clinical caseload, they estimated that $38 \%$ (SD 18; range 2 to 80 ) had severe, $34 \%$ (SD 10; range 18 to 60 ) had moderate and 28\% (SD 16; range 10 to 80 ) had mild arm deficits.

Respondents identified other providers of treatment in addition to therapists included rehabilitation assistants $(\mathrm{n}=44)$, family/carer/friend $(\mathrm{n}=47)$, nursing staff $(\mathrm{n}=5)$, volunteers $(n=3)$. 
Table 1 Treatments used for people with mild upper limb deficits listed by over $10 \%$ of respondents

\begin{tabular}{lll}
\hline Treatments & $\mathbf{n}$ & \% \\
\hline Functional training & 101 & 67 \\
GRASP & 53 & 35 \\
Active and weighted exercise & 29 & 19 \\
CIMT & 25 & 17 \\
Task repetitive strength training & 21 & 14 \\
\hline
\end{tabular}

CIMT, constraint induced movement therapy; GRASP, Graded

Repetitive Arm Supplementary Programme.

\section{Where?}

The majority of respondents were employed in the National Health Service (NHS) $(80 \%$; $\mathrm{n}=132)$ with less than $15 \%(\mathrm{n}=25)$ working in the private sector and $2 \%$ working in a voluntary/third sector $(n=4)$ or high education setting $(\mathrm{n}=3)$.

Therapists $(n=154)$ worked in a variety of settings. From those that reported spending over $75 \%$ of their time in a single setting $(\mathrm{n}=76) 30$ worked in hyperacute/ acute settings $(39 \%), 10$ in general inpatient rehabilitation $(13 \%), 2$ in intermediate care (3\%), 18 in early-supported discharge (24\%), 11 in general community $(15 \%)$ and 5 in outpatients $(7 \%)$. The remainder $(n=78)$ did not spend more than $75 \%$ of their time in a single setting.

\section{What?}

Participants were asked to list treatments that they typically used for people with mild, moderate and severe defi$\operatorname{cits}^{26}$ (defined using the NIH Stroke Scale) of the upper limb after stroke.

\section{Mild deficits}

Respondents reported spending 41\% (SD 26; range 7 to $100 ; n=149$ ) of a typical therapy session on treatments for the upper limb for people with mild deficits. In free text answers, respondents $(n=151)$ listed 30 treatments/interventions that they would typically use as part of treatment. Those used by more than $10 \%$ of respondents are shown in table 1

Seventy-one per cent $(n=110)$ of respondents reported that people with mild deficits of the upper limb were also given unsupervised activities in addition to that provided during sessions with occupational or physiotherapists. This comprised functional training/practice $(n=90)$, exercise programmes $(n=58)$, Graded Repetitive Arm Supplementary Programme (GRASP) and Promoting Recovery of the Arm: Clinical Tools for Intensive Stroke Exercise (PRACTISE) structured upper limb exercise programmes $(\mathrm{n}=49)$, remedial/table top activities (eg, theraputty; $\mathrm{n}=30)$ and sensory re-education $(\mathrm{n}=17)$.

\section{Moderate deficits}

In a typical treatment session, respondents reported spending approximately $45 \%$ (SD 17; range 20 to 90; $\mathrm{n}=151$ ) of the entire session on upper limb activities for
Table 2 Treatments used for people with moderate upper limb deficits listed by over $10 \%$ of respondents

\begin{tabular}{lll}
\hline Treatments & $\mathbf{n}$ & $\%$ \\
\hline Functional training & 63 & 42 \\
Active and weighted exercise & 58 & 38 \\
GRASP & 52 & 35 \\
Mirror box treatment & 29 & 19 \\
CIMT & 23 & 15 \\
\hline
\end{tabular}

CIMT, constraint induced movement therapy; GRASP, Graded Repetitive Arm Supplementary Programme.

people with moderate deficits. Respondents $(n=150)$ listed 25 different treatments for people with moderate arm deficits after stroke, those used by more than $10 \%$ of respondents are shown in table 2 .

Ninety-five per cent of respondents $(n=143)$ reported that people with moderate arm deficits were given additional unsupervised activities. These comprised exercise programmes $(\mathrm{n}=70)$, practice of functional/everyday tasks $(n=50)$, sensory re-education $(n=36)$, GRASP and PRACTISE structured upper limb exercise programmes $(\mathrm{n}=34)$, mirror therapy $(\mathrm{n}=14)$ and positioning $(\mathrm{n}=14)$.

\section{Severe deficits}

Respondents estimated that they spent $35 \%$ (SD 19; range 10 to $90 ; n=149$ ) of a typical treatment session on upper limb treatments for people with severe deficits. From free text answers, respondents $(\mathrm{n}=147)$ listed 16 different treatments for the upper limb in this group. The treatments reported to be used by over $10 \%$ of respondents for this group are displayed in table 3. Seventy-nine per cent of respondents $(n=119)$ reported that people with severe arm deficits typically received additional unsupervised therapy to that provided by occupational and physiotherapists. This included exercise programmes $(n=66)$, sensory re-education/massage $(n=42)$, positioning $(\mathrm{n}=39)$, advice and education $(\mathrm{n}=33)$, mirror therapy $(\mathrm{n}=12)$ and splinting $(\mathrm{n}=12)$.

\section{How much?}

Frequency

Respondents reported that occupational and physiotherapists provided treatment for the upper limb a median of three times a week (range PT: 1 to 7 days, $n=153$; OT: 1 to 6 days, $\mathrm{n}=154)$. The frequency varied depending on setting (figure 2) with patients in inpatient settings receiving somewhat more frequent treatment than those in general community and outpatient settings.

One hundred and ten respondents stated that treatment by others was provided in addition to occupational and physiotherapy, while 44 reported that no one else provided additional therapy. For those indicating that additional therapy was provided it was given a median of three times a week by rehabilitation assistants (range 1 to $7 ; \mathrm{n}=47$ ) and a median of every day by family/carer/ friends (range 3 to $7 ; n=44$ ). 
Table 3 Treatments used for people with severe upper limb deficits listed by over $10 \%$ of respondents

\begin{tabular}{lll}
\hline Treatments & $\mathbf{n}$ & $\%$ \\
\hline Range of movement exercises & 28 & 19 \\
Mirror box treatment & 20 & 14 \\
Functional electrical stimulation & 20 & 14 \\
\hline
\end{tabular}

\section{Duration}

Within each therapy session, respondents estimated typically spending a mean of $28.9 \mathrm{~min}$ (SD 18 ; range 7.5 to 80 ; $\mathrm{n}=154$ ) directly engaged in upper limb treatments ('time on task'). This varied depending on where the patient was based (table 4).

Data of the time spent on treatment in each location is only presented for respondents who reported spending over $75 \%$ of their clinical time in this single area $(n=74)$.

A completed TIDieR checklist is presented in supplementary file 3 and collated data is presented in tables in online supplementary appendix 1 and 2 .

\section{DISCUSSION}

This study utilised elements of a recognised reporting tool, the TIDieR checklist (completed and presented in a online supplementary file 3), ${ }^{4}$ to develop a survey to describe the content of usual therapy reported by occupational and physiotherapists for the upper limb after stroke. Respondents appeared largely representative of the wider UK therapist population, demonstrating a range of academic qualifications, geographical location and experience in
Table 4 Mean reported time spent on upper limb in treatment session by location

\begin{tabular}{lrl}
\hline Location & n & Mean time (minutes, SD) \\
\hline Hyperacute/ acute care & 29 & $21.4(14.2)$ \\
Early supported discharge & 18 & $23.8(12)$ \\
General rehabilitation & 10 & $25.5(14.4)$ \\
Intermediate care & 2 & $25(7)$ \\
General community & 10 & $20.5(15.2)$ \\
Outpatients & 5 & $32(15.2)$
\end{tabular}

stroke rehabilitation. By aligning reported therapy practice across the UK to items of the TIDieR checklist, the survey findings can be used to design clear and replicable standard therapy control interventions to inform future research trials. Furthermore, by providing a detailed description of reported current practice this study highlights gaps between recommended treatments from guidelines and their implementation in clinical settings, guiding future research and rehabilitation service configurations.

However, the survey findings have several limitations. The response rate of the survey is not known because it was distributed electronically via multiple channels. The ACPIN database, which was one channel through which it was circulated, contains over 1000 members, suggesting that the survey's response rate was relatively low but not unexpected for this type of survey. ${ }^{27}$ Efforts were made to increase responses through reminder emails and the use of the professional organisations for distribution provided credibility and anonymity. As the sample

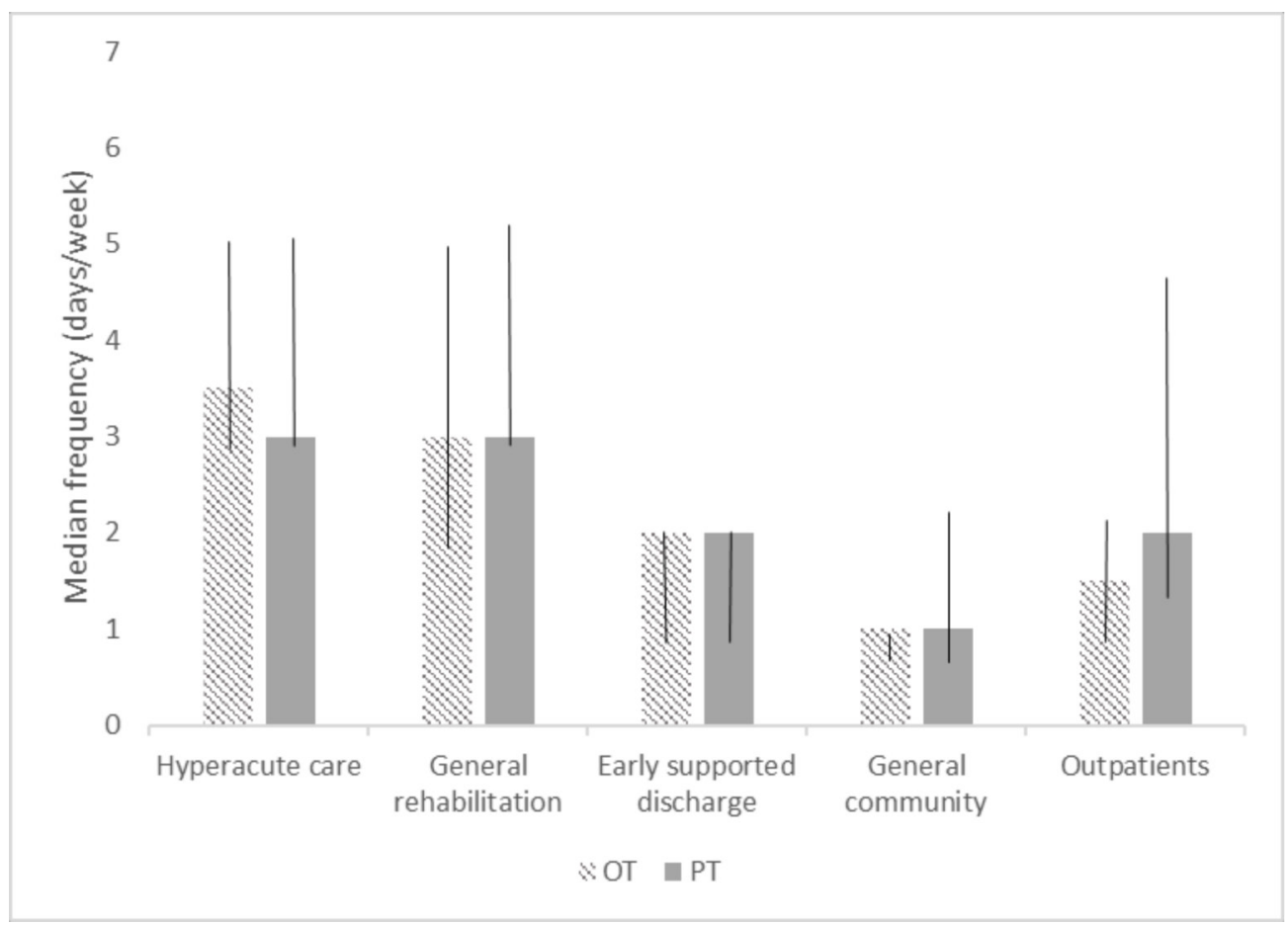

Figure 2 Reported median frequency of therapy provided each week according to location. Error bars denote interquartile range. OT,occupational therapists; PT, physiotherapists. 
size was over 150 the sampling error was reduced ${ }^{27}$ but should still be acknowledged. It is also worth noting that there were very little missing data, with only two (subsequently excluded) respondents omitting more than $50 \%$ of items. This suggests that although some people chose not to open the survey, those that did completed it diligently. It is also likely that respondents were motivated and interested in upper limb rehabilitation. This and the greater number of physiotherapist respondents and the relatively long average time since qualification (16 years) may introduce some unavoidable bias in responses which should be considered when interpreting the results.

Severe and moderate arm deficits were the largest proportion treated most frequently by respondents, with mild deficits being seen much less often. Despite a slight preponderance in moderate severity arm impairments in the current study, these proportions appear broadly similar to those reported by others after stroke, although direct comparison between studies is hindered by the range of outcome tools used to classify to arm function. ${ }^{28}{ }^{29}$ The survey found that, on average, respondents reported providing upper limb therapy for 29 minutes three times a week, although both these parameters varied depending on the setting. An interesting finding was that the reported average time of upper limb treatment per session $(29 \mathrm{~min})$ was considerably more than that reported in observational studies. In systematic reviews, between 4 to $17 \mathrm{~min}$ of therapy was spent on upper limb activity and/or other treatments in a typical session. ${ }^{10} 30$ The greater intensity of therapy reported in this survey could suggest a selection bias as those therapists who were motivated and able to provide more upper limb therapy might have been more likely to complete the survey. It could also indicate, as observed by others, that therapists may have overreported or struggled to accurately recall the actual time spent on treatment. ${ }^{31}$ However, the differences in findings between studies might reflect different interpretations as to what upper limb therapy actually comprises in this study as some therapists may have considered the time to include activities where the upper limb was likely to benefit from therapy, but was not the direct target of intervention (eg, aerobic exercise). ${ }^{32} 33$ This ambiguity might be an inevitable limitation of the current study's findings, but focus on content of therapy and who delivered it attempted to minimise this effect by providing some guidance to therapists on what did, and what did not, constitute therapy.

An unanticipated and novel finding is the majority of respondents noted that they provided additional activities and that others supplemented therapy for people after stroke. On average this was provided on a daily basis by family/carers $(n=44)$ and three times a week by rehabilitation assistants $(n=47)$. This is the first study to highlight the provision of additional therapy as a component of standard therapy and indicates that this extra input should be recognised when considering replicating standard treatment in trials. Despite this, the findings of this survey indicate that the reported overall dose of therapy is relatively small when compared with what is known to be effective from animal models of stroke rehabilitation ${ }^{34}$ and so may not realise the potential for recovery. This argument is supported by findings from other studies; several large, well-conducted trials offering similar amounts of upper limb therapy to those reported in the current study found minimal benefit ${ }^{3536}$ while trials that used higher doses reported meaningful and significant changes. ${ }^{3738}$ In addition to research trials, large improvements in upper limb functioning have been reported in a NHS-funded clinical service (the Queen's Square Upper Limb Programme) that delivers 90 hours of multidisciplinary upper limb rehabilitation over 3 weeks. ${ }^{33}$ When the intensities of therapy in these studies are compared with those measured in observational studies, ${ }^{32}{ }^{39}$ SSNAP data $^{8}$ and the current study, they emphasise that service provision for rehabilitation of the upper limb after stroke needs radical alteration if it is to empower therapists to provide effective therapy and maximise recovery for people after stroke. Further research is therefore urgently needed to find ways to upscale services so that they can deliver greater intensities of high-quality, personalised, evidence-based therapy for the upper limb in clinical practice.

The findings indicate that several well-evidenced and recommended clinical treatments (eg, Constraint Induced Movement Therapy and the Graded Repetitive Arm Supplementary Programme) were reported to be used by respondents. Other treatments with an emerging evidence base were not reported to be used often (eg, Functional Electrical Stimulation). Interestingly, repetitive task training, a treatment in which participants repeatedly practise a task or goal-oriented movement, was not explicitly listed by any participant, despite being recommended in guidelines and supported by a relatively robust evidence base ${ }^{2440}$ However, it is possible that respondents' use of 'functional training' to describe their treatments could have been analogous to repetitive task training, but this cannot be verified. Some respondents did report using 'task specific strength training' (mild: $\mathrm{n}=21$; moderate: $\mathrm{n}=11$ ) but, as this terminology is not widely utilised in rehabilitation literature it is unclear what it comprises. The focus of therapy towards functional activities found in this study supports other reports of practice in the $\mathrm{UK}^{23}$ and treatments for mild and moderate upper limb deficits showed considerable similarities between respondents. While others have reported somewhat greater consensus for the use of functional activities in therapy (over $88 \%$ for mild and moderate deficits), this may be due to different survey approaches and the use of an expert panel to interpret and express consensus on the data. ${ }^{23}$ In contrast, there was a notable lack of consistency in the treatment choices reported for people with severe deficits of the upper limb; the most commonly given treatment (range of motion) was only listed by $19 \%$ of 107 respondents. This may reflect therapists' uncertainty about the recovery of the severely impaired upper limb and the current absence of specific guidance and established effective therapies for rehabilitation after severe stroke. ${ }^{41}$ It is 
also possible that the variability in treatments for those with severe deficits is because of the influence of other factors which tend to accompany more severe deficits after stroke (for example worse pre-stroke status, older age and medical complications). Indeed, it has been found that patients who had a milder stroke, were younger, male, had fewer medical complications and had received thrombolysis tended to receive more intensive therapy after stroke. ${ }^{42}$ These findings highlight that better understanding of the factors that influence clinicians' professional decision-making about treatment content and intensity is worthy of further investigation to guide clinical care.

The findings also showed that other evidence-based and recommended treatments (such as mental imagery) are not widely implemented in clinical practice. ${ }^{24}$ This is perhaps not surprising as only a small fraction $(2.5 \%)$ of published stroke rehabilitation research in journals evaluate the implementation of evidence-based interventions into healthcare practice. ${ }^{43}$ This indicates that further investigation is warranted to determine why some treatments are implemented and others are not and suggests that a greater focus on how recognised effective treatments can become part of routine clinical care is needed.

\section{CONCLUSIONS}

This survey has identified the commonly reported upper limb treatments that are provided for people after stroke by occupational and physiotherapists. These results are not intended to provide an exemplar or template for clinical practice or represent best practice and are limited by an unknown response rate and the self-reported nature of the data. However, they can be used to reflect current practice in the UK and provide a detailed point of reference to aid the development of standard therapy interventions in research trials.

The findings indicate that some evidence-based treatments appear to be more widely implemented in routine clinical practice than others and that while there is considerable consensus in the treatments used for mild and moderate upper limb deficits, there was much less consistency in the treatments used with people with severe deficits. The results also indicate that the intensity of therapy is less than that shown to be effective in rehabilitation studies.

Future work could seek to identify the optimally effective treatments for different severities of upper limb involvement after stroke and qualitatively explore the rationale for treatment selection. Finding ways to deliver more intensive therapy in practice is also urgently required and the development of new treatments should explicitly consider how they can be adopted into clinical practice. The findings of the current study contribute to these endeavours by providing a detailed description of self-reported, clinically realistic upper limb therapy which can inform the design, interpretation and implementation of future stroke rehabilitation research.
Acknowledgements The authors wish to thank all the therapists who took the time to complete the survey, without their willingness to provide detailed and comprehensive answers the survey could not have been conducted. They also wish to thank Ethan Farrell for his technical assistance.

Contributors RS developed the idea and undertook analysis of the results and drafted the paper. RP conducted analysis of the data and drafted the paper. LC developed the idea, oversaw analysis and drafted the paper. $\mathrm{KJ}$ developed the idea, oversaw analysis and drafted the paper.

Funding This work was supported by the Lancashire Institute for Global Health (LIFE) Grant number LSSM2.

Map disclaimer The depiction of boundaries on the map(s) in this article do not imply the expression of any opinion whatsoever on the part of BMJ (or any member of its group) concerning the legal status of any country, territory, jurisdiction or area or of its authorities. The map(s) are provided without any warranty of any kind, either express or implied.

Competing interests None declared.

Patient consent for publication Not required.

Ethics approval The survey gained ethical approval from the Science Technology, Medicine and Health Ethics panel at the University of Central Lancashire (reference number: 869).

Provenance and peer review Not commissioned; externally peer reviewed.

Data availability statement Data are available here D0I: 10.17030/uclan.data. 00000199

Open access This is an open access article distributed in accordance with the Creative Commons Attribution Non Commercial (CC BY-NC 4.0) license, which permits others to distribute, remix, adapt, build upon this work non-commercially, and license their derivative works on different terms, provided the original work is properly cited, appropriate credit is given, any changes made indicated, and the use is non-commercial. See: http://creativecommons.org/licenses/by-nc/4.0/.

\section{ORCID iD}

Rachel Stockley http://orcid.org/0000-0003-4441-6860

\section{REFERENCES}

1. Stroke Association. State of the nation: stroke statistics. London, 2017.

2. G. BROEKS, J, Lankhorst GJ, Rumping K, et al. The long-term outcome of arm function after stroke: results of a follow-up study. Disabil Rehabil 1999;21:357-64.

3. Chen C-M, Tsai C-C, Chung C-Y, et al. Potential predictors for health-related quality of life in stroke patients undergoing inpatient rehabilitation. Health Qual Life Outcomes 2015;13:118.

4. Hoffmann TC, Glasziou PP, Boutron I, et al. Better reporting of interventions: template for intervention description and replication (TIDieR) checklist and guide. BMJ 2014;348:91687.

5. Lohse KR, Pathania A, Wegman R, et al. On the reporting of experimental and control therapies in stroke rehabilitation trials: a systematic review. Arch Phys Med Rehabil 2018;99:1424-32.

6. Laver KE, Lange B, George S, et al. Virtual reality for stroke rehabilitation. Cochrane Database Syst Rev 2017;31.

7. Laver KE, George S, Thomas S, et al. Virtual reality for stroke rehabilitation. Cochrane Database Syst Rev 2015;17.

8. Intercollegiate Stroke Working Party. Sentinel stroke national audit programme 2017.

9. de Jong LD, van Wijck F, Stewart RE, et al. Content of conventional therapy for the severely affected arm during subacute rehabilitation after stroke: an analysis of physiotherapy and occupational therapy practice. Physiotherapy Research International 2018;23.

10. Serrada I, McDonnell MN, Hillier SL. What is current practice for upper limb rehabilitation in the acute hospital setting following stroke? A systematic review. NeuroRehabilitation 2016;39:431-8.

11. Narayan Arya K, Verma R, Garg RK, et al. Meaningful task-specific training (MTST) for stroke rehabilitation: a randomized controlled trial. Top Stroke Rehabil 2012;19:193-211.

12. McDonnell MN, Hillier SL, Esterman AJ. Standardizing the approach to evidence-based upper limb rehabilitation after stroke. Top Stroke Rehabil 2013;20:432-40.

13. Jarvis K, Reid G, Edelstyn N, et al. Development of the occupational therapy stroke arm and hand record: an upper limb treatment schedule. Br J Occup Ther 2014. 
14. Lang CE, Wagner JM, Edwards DF, et al. Upper extremity use in people with hemiparesis in the first few weeks after stroke. J Neurol Physical Ther 2007;31:56-63.

15. Lang CE, MacDonald JR, Reisman DS, et al. Observation of amounts of movement practice provided during stroke rehabilitation. Arch Phys Med Rehabil 2009;90:1692-8.

16. Kimberley TJ, Samargia S, Moore LG, et al. Comparison of amounts and types of practice during rehabilitation for traumatic brain injury and stroke. JRRD 2010;47:851-62.

17. Sjöholm A, Skarin M, Churilov L, et al. Sedentary behaviour and physical activity of people with stroke in rehabilitation hospitals. Stroke Res Treat 2014;2014:1-7.

18. Åstrand A, Saxin C, Sjöholm A, et al. Poststroke physical activity levels no higher in rehabilitation than in the acute Hospital. J Stroke Cerebrovasc Dis 2016;25:938-45.

19. Bernhardt J, Chitravas N, Meslo IL, et al. Not all stroke units are the same: a comparison of physical activity patterns in Melbourne, Australia, and Trondheim, Norway. Stroke 2008;39:2059-65.

20. Hokstad A, Indredavik B, Bernhardt J, et al. Hospital differences in motor activity early after stroke: a comparison of 11 Norwegian stroke units. J Stroke Cerebrovas Dis 2015;24:1333-40.

21. De Wit L, Putman K, Dejaeger E, et al. Use of time by stroke patients: a comparison of four European rehabilitation centers. Stroke 2005;36:1977-83.

22. Connell L, McMahon N, Eng J, et al. Prescribing upper limb exercises after stroke: a survey of current UK therapy practice. J Rehabil Med 2014;46:212-8.

23. McHugh G, Swain ID, Jenkinson D. Treatment components for upper limb rehabilitation after stroke: a survey of UK national practice. Disabil Rehabil 2014;36:925-31.

24. Royal College of Physicians. National clinical guideline for stroke 2016.

25. Kelley K, Clark B, Brown V, et al. Good practice in the conduct and reporting of survey research. Int $J$ Qual Health Care 2003;15:261-6.

26. Stroke Scales and Related Information. National Institute of neurological disorders and stroke. Available: https://www.ninds.nih. gov/node/12266 [Accessed 25 Feb 2019].

27. Fowler F. Survey research methods. 4th ed. Thousand Oaks, CA, USA: SAGE Publications, Inc, 2009.

28. Stinear CM, Byblow WD, Ackerley SJ, et al. Prep2: a biomarkerbased algorithm for predicting upper limb function after stroke. Ann Clin Transl Neurol 2017;4:811-20.

29. Persson HC, Parziali M, Danielsson A, et al. Outcome and upper extremity function within 72 hours after first occasion of stroke in an unselected population at a stroke unit. A part of the SALGOT study. BMC Neurol 2012;12:162.
30. Hayward KS, Brauer SG. Dose of arm activity training during acute and subacute rehabilitation post stroke: a systematic review of the literature. Clin Rehabil 2015;29:1234-43.

31. Kaur G, English C, Hillier S. How physically active are people with stroke in physiotherapy sessions aimed at improving motor function? A systematic review. Stroke Res Treat 2012;2012:1-9.

32. Taylor E, Jones F, McKevitt C. How is the audit of therapy intensity influencing rehabilitation in inpatient stroke units in the UK? an ethnographic study. BMJ Open 2018;8:e023676.

33. Ward NS, Brander F, Kelly K. Intensive upper limb neurorehabilitation in chronic stroke: outcomes from the Queen square programme. $J$ Neurol Neurosurg Psychiatry (Published Online First: 15 February 2019).

34. Krakauer JW, Carmichael ST, Corbett D, et al. Getting neurorehabilitation right: what can be learned from animal models? Neurorehabil Neural Repair 2012;26:923-31.

35. Winstein CJ, Wolf SL, Dromerick AW, et al. Effect of a Task-Oriented rehabilitation program on upper extremity recovery following motor stroke: the ICARE randomized clinical trial. JAMA 2016;315:571-81.

36. Lang CE, Strube MJ, Bland MD, et al. Dose response of taskspecific upper limb training in people at least 6 months poststroke: a phase II, single-blind, randomized, controlled trial. Ann Neurol 2016;80:342-54.

37. McCabe J, Monkiewicz M, Holcomb J, et al. Comparison of robotics, functional electrical stimulation, and motor learning methods for treatment of persistent upper extremity dysfunction after stroke: a randomized controlled trial. Arch Phys Med Rehabil 2015;96:981-90.

38. Daly JJ, McCabe JP, Holcomb J, et al. Long-Dose intensive therapy is necessary for strong, clinically significant, upper limb functional gains and retained gains in Severe/Moderate chronic stroke. Neurorehabil Neural Repair 2019;33:523-37.

39. Clarke DJ, Burton L-J, Tyson SF, et al. Why do stroke survivors not receive recommended amounts of active therapy? findings from the react study, a mixed-methods case-study evaluation in eight stroke units. Clin Rehabil 2018;32:1119-32.

40. French B, Thomas LH, Coupe J, et al. Repetitive task training for improving functional ability after stroke. Cochrane Database Syst Rev 2016;19.

41. Hayward K, Barker R, Brauer S. Interventions to promote upper limb recovery in stroke survivors with severe paresis: a systematic review. Disabil Rehabil 2010;32:1973-86.

42. McGlinchey MP, Paley L, Hoffman A, et al. Physiotherapy provision to hospitalised stroke patients: analysis from the UK sentinel stroke national audit programme. Eur Stroke J 2018;2396987318800543.

43. Lynch EA, Chesworth BM, Connell LA. Implementation-The missing link in the research translation pipeline: is it any wonder no one ever implements evidence-based practice? Neurorehabil Neural Repair 2018;32:751-61. 